\title{
ERRATUM
}

\section{Naturally occurring dominant-negative SK3 channel isoform}

H Tomita, VG Shakkottai, GA Gutman, G Sun, WE Bunney, MD Cahalan, KG Chandy and JJ Gargus

Molecular Psychiatry (2003) 8, 766. doi:10.1038/sj.mp.4001407

Correction to: Molecular Psychiatry (2003) 8, 460. doi: 10.1038/sj.mp.4001358

We regret that the last author's name was spelled incorrectly. The correct spelling is shown above. 